\title{
A Mini-Review for an Adsorption of Polycyclic Aromatic Hydrocarbons (PAHs) by Physical Gel
}

\author{
Siu-Kan Law ${ }^{1}$ (D), Yat-Hei Fung 1(D), Hiu-Ying Chan 1(D), Jie Han 1,* (D) ,Chui-Man Lo 1,2,* (D), \\ Ho-Wai Wong ${ }^{3}$ (D)
}

1 Department of Science, School of Science and Technology, Hong Kong Metropolitan University, Ho Man Tin, Kowloon, Hong Kong, China

2 Department of Chemistry, The Chinese University of Hong Kong, Shatin, New Territories, Hong Kong, China

3 Faculty of Medicine, The Chinese University of Hong Kong, Shatin, New Territories, Hong Kong, China

* Correspondence: cmlo@cuhk.edu.hk (C.-M.L); chan@ouhk.edu.hk (J. H.) ;

Scopus Author ID 57193752045 (C.M.L.); 57199890667 (J.H.);

Received: 14.10.2021; Revised: 20.11.2021; Accepted: 24.11.2021; Published: 9.11.2021

\begin{abstract}
On 4 December in 2002, the mainstream source of exposure to Polycyclic Aromatic Hydrocarbons (PAHs) was defined by the Scientific Committee as food and inhaled air. Several Polycyclic Aromatic Hydrocarbons (PAHs) such as benzo[a]pyrene, chrysene, and dibenzo(a,h)anthracene in food caused the risk of human health. These are produced by the cooking processes, including combustion processes and pyrolysis sources. Certain food preparation methods like grilling, roasting, and smoking are accumulated PAHs in the sink pipes. As PAHs are toxic and carcinogenic, it raises health and environmental problems. What is the method for preventing PAHs exist in wastewater? This review article introduces a functional material, gelatin physical gels, to trap and remove the PAHs. The physical gel changes from colorless to pale yellow during the adsorption of PAHs in household wastewater. The concentration of PAHs is determined by GC-MS analysis, which decreases the potential risk of human exposure in an environment with PAHs.
\end{abstract}

Keywords: polycyclic aromatic hydrocarbons (PAHs); physical gel; wastewater.

(C) 2021 by the authors. This article is an open-access article distributed under the terms and conditions of the Creative Commons Attribution (CC BY) license (https://creativecommons.org/licenses/by/4.0/).

\section{Introduction}

Polycyclic aromatic hydrocarbons (PAHs) are organic compounds with two or more fused aromatic rings in linear, angular, or cluster arrangements [1]. These are naturally found in the environment or created primarily by incomplete combustion of organic matter such as burning fossil fuels, coal, oil, and gas. Garbage, sewage sludge, or tobacco smoke tend to bioaccumulate within an environment [2].

PAHs have a high hydrophobicity and low water solubility [3] but a high octanol-water partition coefficient. Those properties make PAHs persistent and easy to exist everywhere, e.g., fluoranthene, phenanthrene, and pyrene have a different half-life in various environments (Table 1).

Table 1. The half-life of fluoranthene, phenanthrene, and pyrene in a different environment [4].

\begin{tabular}{l|l|l|l|l} 
PAHs & Soil & Air & Surface water & Groundwater \\
\hline Fluoranthene & 140 days -1.2 years & $2.0-20.2$ hours & $21-63$ hours & 280 days -2.4 years \\
\hline Phenanthrene & $16-200$ days & $2-20.1$ hours & $3-25$ hours & 32 days -1.1 years \\
\hline Pyrene & 210 days -5.2 years & $0.7-2.0$ hours & $0.7-2.0$ hours & $1.2-10.4$ years
\end{tabular}


On the EFSA in 2008, the European Food Safety Authority has identified and estimated that there are about 500 PAHs detected in ambient air. PAHs are classified into two groups: (i) Low molecular weight (LMW), contain less than or equal to three aromatic rings; (ii) High molecular weight (HMW) contains more than or equal four aromatic rings.

The hydrophobicity of PAHs generally depends on the increases of molecular mass, with aqueous solubility decreasing from the range of low $\mathrm{mg} / \mathrm{L}$ for LMW PAHs to about 1 $\mu \mathrm{g} / \mathrm{L}$ of HMW PAHs [5].

PAHs are difficult to degrade under natural conditions. As a result, it accumulates as a long-term hydrophobic contaminant in the environment and must be removed by adsorption or bio-degradation from contaminated wastewater. From December 2001 to June 2005, the concentration of total PAHs in surface sediments ranging from $36.5 \mathrm{ng} / \mathrm{g}$ to $256.3 \mathrm{ng} / \mathrm{g}$ in the Mai Po Inner Deep Bay, Ramsar Site of Hong Kong. It is nearly 10 times [6].

\section{Polycyclic aromatic hydrocarbons (PAHs).}

PAHs are organic molecules that are widely found in the environment, usually as a result of organic material incomplete combustion (e.g., coal, oil, petrol, and wood) [7]. Some common PAHs, namely naphthalene, phenanthrene, pyrene, chrysene, dibenzo(a,h)anthracene, and benzo(a)pyrene (Figure 1).

\subsection{Naphthalene.}

It has two benzene rings with a distinctive aroma which is frequently used as mothballs and leather. It is a white, pale brown solid with a strong odor. Naphthalene can dissolve in most organic, carbon-containing solvents but not in water. This may cause hemolytic anemia, but no evidence is associated with human or animal cancer. Naphthalene exposure at a high level is toxic to wildlife, especially aquatic organisms. However, naphthalene can break down rapidly in the environment, and only huge discharges are likely to cause harmful effects. Naphthalene binds weakly to soils while bacteria can break it down. Therefore, it is not accumulated in wildlife [8].

\subsection{Phenanthrene.}

It is the formation of three aromatic rings in a molecular weight of $178.23 \mathrm{~g} / \mathrm{mol}$. It is commonly found in the incomplete combustion of woods and fossil fuels. It is a widespread compound in an aquatic environment and exists in tap water, wastewater, surface water, lake sediments in dried form, etc. Seafood, smoked and charcoal-broiled foods, grass, tree leaves, spruce needles, and plants also have phenanthrene [9].

\subsection{Pyrene.}

It is a potentially toxic compound consisting of four fused aromatic rings with a molecular weight of $202.25 \mathrm{~g} / \mathrm{mol}$. Its appearance is colorless and crystal-like solid. This is usually used to make dyes, plastics, and pesticides. Incomplete combustion in smoke from coal, oil, wood-burning stoves, emissions from cigarette smoke, motor vehicle exhaust, and furnaces releases pyrene into the environment [10]. 


\subsection{Chrysene.}

It consists of four fused aromatic rings with $228.3 \mathrm{~g} / \mathrm{mol}$ molecular weight. It is an aromatic hydrocarbon allied to naphthalene and anthracene, which is found in coal tar. Chrysene exists in a white crystalline solid, which is insoluble in water. Chrysene is an environmental hazard that causes toxicity with long-lasting effects on marine life [11].

\subsection{Dibenzo(a,h)anthracene.}

It is a five fused aromatic rings-compound with a linear structure and molecular weight of $278.3 \mathrm{~g} / \mathrm{mol}$. It usually appears as white crystals or yellow solid, found in tobacco smoke, pitch, and certain food products, toxic with long-lasting effects on marine life. Dibenz(a,h)anthracene is going to emit acrid smoke if it gets heated. It has harmful effects on the human swallow or inhalation [12].

\subsection{Benzo(a)pyrene.}

It is a five fused aromatic rings-compound with a molecular weight of $252.3 \mathrm{~g} / \mathrm{mol}$. It is primarily found in gasoline, coal tar, and charcoal-broiled foods. This is in a liquid formed or pale yellow crystals. Benzo(a)pyrene presents a threat to the environment as it easily penetrates the soil and contaminates groundwater or nearby waterways. It harms the ingestion or inhalation [13].<smiles>c1ccc2ccccc2c1</smiles>

(a)<smiles>c1ccc2c(c1)cc1ccc3cccc4ccc2c1c34</smiles>

(d)

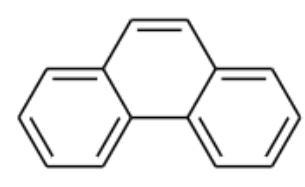

(b)

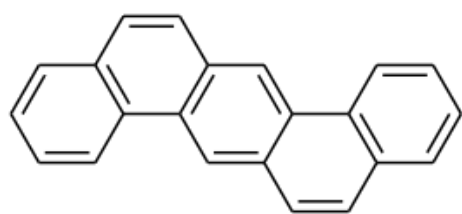

(e)<smiles>c1cc2ccc3cccc4ccc(c1)c2c34</smiles>

(c)<smiles>c1ccc2c(c1)ccc1c3ccccc3ccc21</smiles>

(f)

Figure 1. Structure of PAHs. (a) Naphthalene; (b) phenanthrene; (c) pyrene; (d) benzo(a)pyrene;

(e) dibenzo(a,h)anthracene; (f) chrysene.

\section{Physical gels}

There are different types of physical gel, including gelatin, chitosan, silica, and organogel. These can be classified according to their physical and chemical properties.

\subsection{Gelatin.}

Gelatin is a biopolymer that is mainly made of a kind of animal protein (Figure 2) [14]. It has a colorless or pale yellow appearance and is derived from collagen of animal body parts. A huge amount of glycine, proline, and hydroxyproline groups have consisted in gelatin, which forms a transparent gel with cooling under $35^{\circ} \mathrm{C}$ while it is the melting point of gelatin. Gelatin films are flexible, clear, strong, and permeable to oxygen. Drying temperature can influence 
the properties of gelatin films. Due to the magnificent ability of film-forming and fast dissolution in gastric fluids, it is widely chosen to produce capsules. Since gelatin is a low-cost product, it is attractive for practical application. It is used as the solvents for preparing candy, marshmallows, and desserts for food production. In biomedical and pharmaceutical fields, it is used in bone regeneration and the delivery of drugs because of its biodegradability and biocompatibility in physiological conditions [15].

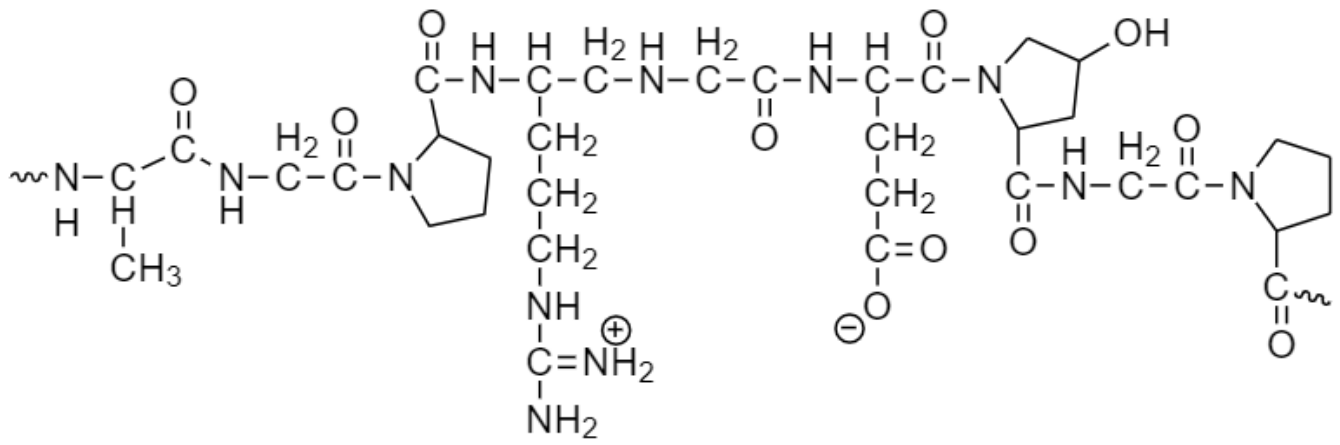

Figure 2. Structure of gelatin.

\subsection{Chitosan.}

Chitosan forms with amino polysaccharides produced by chitin deacetylation (Figure 3) [16]. It is a biopolymer from the by-product in insects and the waste of crustaceans, such as shrimps and crabs. This is organic and naturally found in the environment. Chitosan contains amino and hydroxyl groups. It is soluble in acidic aqueous solutions and more chemically versatile than others. The main characteristics of chitosan are the molecular weight and the degree of acetylation due to its diverse bioactive attributes, materials-forming capacity to biodegradability, and solubility. Chitosan also has antimicrobial properties affected by $\mathrm{pH}$ value, degree of acetylation, and molecular weight. As chitosan is biocompatible, biodegradable, and non-toxic, it is environmentally friendly [17].

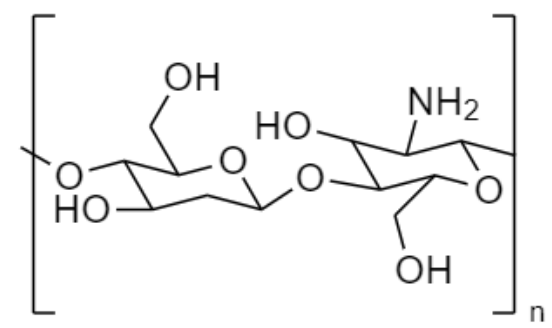

Figure 3. Structure of chitosan.

\subsection{Silica gel.}

Silica gel forms silicon dioxide $\left(\mathrm{SiO}_{2}\right)$ in the amorphous and porous form (Figure 4) [18]. It is commonly used as a desiccant or drying agent to control the humidity avoiding spoilage or degradation of the food or consumables in the form of beads for a small paper packet. Silica gel is a generative absorbent of silica with weakly acidic properties produced from sodium silicate $\left(\mathrm{Na}_{2} \mathrm{SiO}_{3}\right)$ and sulfuric acid $\left(\mathrm{H}_{2} \mathrm{SO}_{4}\right)$. The hydrophilic surface of silica gel can be modified, rendering lipophilic to absorb PAHs. A series of hydrophobic compounds coat on the silica gel to ensure the molecules are attached to the surface through hydrogen bonding or dipole-dipole interactions of the $\mathrm{Si}-\mathrm{OH}$ functional group. Silica gel is used in 
column chromatography to separate analytes from interfering compounds according to their chemical polarity [19].<smiles>O[Si](O)(O)O[Si](O)(O)O[Si](O)(O)O</smiles>

Figure 4. Structure of silica gel.

\subsection{Organogel.}

Organogel is formed by different kinds of oil such as castor, cod liver, sunflower oil, flax-seed, corn, peanut, and extra virgin olive. It is an organo-gelator causing different properties. Monoglyceride (MG) is a low molecular weight compound. This is common to make as a monoglyceride-based organo-gel since saturated monoglycerides are widely used as an emulsifier in a large number of food recipes. It has been found that amphiphiles based on aromatic amino acids (phenylglycine) with amides, ester groups, and long fatty acyl chains can be used to produce organogels selectively in combustible hydrocarbon solvents including hexane, cyclohexane, heptane, pump-oil, diesel, and kerosene at room temperature. Organogel is usually applied in drug delivery [20].

\section{Removal of Polycyclic aromatic hydrocarbons (PAHs)}

\subsection{Physical methods.}

Low-density polyethylene (LDPE) is the simplest way to remove PAHs from water, such as benzo[a]pyrene, fluoranthene, and pyrene. The LDPE sheet is a combination of five polyethylene sheets used as a partition in the chamber. After removing the PAHs from the sheet peeled off, using high-performance liquid chromatography (HPLC) with selective fluorescence detection, migrate to the depth of the PAHs in the foils. The migration process from PAH to $\mathrm{PE}$ is characterized by one-dimensional diffusion in the polyethylene body. $\mathrm{PAH}$ is mainly adsorbed on the surface of the polyethylene and then migrates to the bulk polymer [21].

\subsection{Chemical methods.}

PAHs are broken down through an oxidation reaction. The oxidizing agents' ozone and potassium permanganate convert PAHs into alcohol, acid, and aldehyde derivatives (Figure 5) [4, 22-23]. These become more water-soluble and easier to tackle.

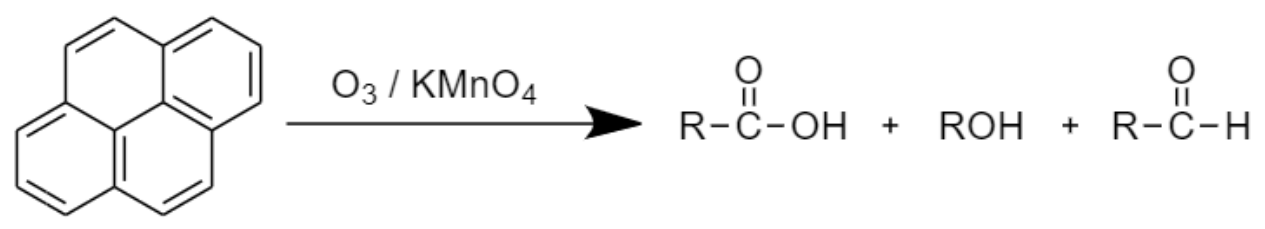

Figure 5. PAHs undergo an oxidation reaction.

\subsection{Biological methods (biodegradation).}

The biodegradation of PAHs is utilized by bacteria and fungi. It is usually conducted to remove the mangrove sediment or other soil samples. PAHs are biodegraded by the 
microorganisms in wastewater, soil, and reservoir sample. Selenastrum capricornutum is a kind of green microalgae that has been proven to remove PAHs under free and alginate immobilized conditions [24].

\subsection{Wastewater treatment in Hong Kong.}

Wastewater treatment plants (WWTPs) are widely used to eliminate PAHs. Chemical and biological treatments have been adopted in the Stonecutter and Shatin Sewage Treatment Works in Hong Kong [25]. PAHs are collected and directed into the WWTP influent stream through the sewer systems. Some PAHs are broken down during the WWTP processes, watersoluble PAHs exit in the treated effluent stream and the remaining adsorb onto particles. This is concentrated in the sludge stream.

The wastewater treatment process of Hong Kong sewage treatment plants has been divided into five parts: preliminary treatment/screening, primary treatment, secondary treatment, tertiary treatment, and chemically enhanced primary treatment [26].

\subsubsection{Preliminary treatment.}

It includes screening and removal of coarse particles. The solid is larger than the diameter of $6 \mathrm{~mm}$ is removed from the collected sewage sample, which is a removal of grit, screening, and sedimentation process. To remove solid waste and settleable suspended solids from wastewater, the total suspended solids (TSS) removal efficiency is approximately $70 \%$, and the biochemical oxygen demand (BOD) is approximately $30 \%$.

\subsubsection{Secondary treatment.}

Of sewage uses biological treatment technology to purify after primary treatment. Microorganisms decompose and settle the organic matter and nutrients in wastewater in the biological process. The effluent treated by this process meets the standards of TSS $30 \mathrm{mg} / \mathrm{L}$ and BOD 20mg/L.

\subsubsection{Tertiary treatment.}

It is the highest level wastewater treatment that refines the treated effluent in the secondary wastewater treatment process. This process generally includes physical and biological processes that further remove nutrients and suspended solids in the wastewater.

\subsubsection{Chemically enhanced primary treatment.}

Alum or ferric salts and polyelectrolytes are sometimes used in the primary treatment to improve TSS and BOD removal. This process's TSS and BOD removal efficiencies are $80 \%$ and $60 \%$, respectively.

In 2004, Toxic Substances Monitoring Programme was developed by the Environmental Protection Department, Hong Kong, which used to observe Hong Kong's marine environment. The extent of substance pollution such as biota, sediment, marine water, and potential land-based pollution sources will be assessed in the program. Sewage effluent is similar to storm runoff and river water, so it is not included as a factor for monitoring. About 40 chemicals are being monitored from the above water sample since 2010, including fluoride, phenol, nonylphenol, nonylphenol ethoxylates, heavy metals (total and methyl mercury $(\mathrm{Hg})$ ), 
tributyltin (TBT), polyaromatic hydrocarbons (PAHs), selected persistent organic pollutants (POPs) under the Stockholm Convention etc. [27].

This program monitors $16 \mathrm{PAH}$ compounds, including acenaphthene, acenaphthylene, anthracene, benzo(a)anthracene, benzo(a)pyrene, benzo(b)fluoranthene, benzo(k)fluoranthene, benzo(ghi)perylene, chrysene, dibenzo(ah)anthracene, fluoranthene, fluorene, indeno(123cd)pyrene, naphthalene, phenanthrene, and pyrene. The degree of compliance of PAHs with local and international standards refers mainly to the standards adopted by NOAA and USEPA (Table 2). If the standards for chemicals cannot be found in the NOAA and USEPA lists, the standards from Canada, the European Union, and Australia are used for comparison (Table 3) [28].

Table 2. International standards of PAHs in wastewater.

\begin{tabular}{l|c|c|l}
\multicolumn{1}{c|}{ Agency } & Focus & Levels & \multicolumn{1}{|c}{ Comments } \\
\hline $\begin{array}{l}\text { U.S. Environmental } \\
\text { Protection Agency }\end{array}$ & Water & $0.001 \mathrm{ppm}$ & $\begin{array}{l}\text { Maximum contaminant level for } \\
\text { benzo(a)anthracene }\end{array}$ \\
\cline { 3 - 4 } & & $\begin{array}{l}\text { Maximum contaminant level for } \\
\text { benzo(a)pyrene, } \\
\text { benzo(b)fluoranthene, } \\
\text { benzo(k)fluoranthene, } \\
\text { chrysene }\end{array}$ \\
\cline { 3 - 4 } & $0.0002 \mathrm{ppm}$ & $\begin{array}{l}\text { Maximum contaminant level for } \\
\text { dibenzo(a,h)anthracene }\end{array}$ \\
\cline { 2 - 4 } & $0.0003 \mathrm{ppm}$ & $\begin{array}{l}\text { Maximum contaminant level for } \\
\text { indenol(1,2,3-c,d)pyrene }\end{array}$
\end{tabular}

Table 3. Hong Kong standards of PAHs in wastewater [27].

\begin{tabular}{l|c|c} 
Contaminants & $\begin{array}{c}\text { Lower Chemical Exceedance } \\
\text { Level (LCEL) }\end{array}$ & $\begin{array}{c}\text { Upper Chemical Exceedance } \\
\text { Level (UCEL) }\end{array}$ \\
\hline Organic-PAHs (ug/kg dry wt.) & 550 & 3160 \\
\hline Low molecular weight PAHs* & 1700 & 9600 \\
\hline High molecular weight PAHs** & \multicolumn{2}{|c}{$\begin{array}{c}180 \\
\text { Organic-non-PAHs } \\
\text { (ug/kg dry wt.) }\end{array}$} \\
\hline $\begin{array}{l}\text { Total PCBs } \\
\text { *Low relative molecular mass PAHs including acenaphthene, acenaphthylene, anthracene, fluorene, }\end{array}$ \\
$\begin{array}{l}\text { naphthalene, and phenanthrene. } \\
\text { **PAHs in high relative molecular mass including benzo[a]anthracene, benzo[a]pyrene, chrysene, }\end{array}$ \\
dibenzo[a,h]anthracene, fluoranthene, pyrene, benzo[b]fluoranthene, benzo[k]fluoranthene, \\
indeno[1,2,3-c,d]pyrene and benzo[g,h,i]perylene.
\end{tabular}

The maximum pollutant level for benzo (a) pyrene in drinking water is 0.02 parts per billion (ppb) [29]. The impact of polycyclic aromatic hydrocarbons on human health and the level of environmental exposure of polycyclic aromatic hydrocarbons are unknown. Still, people who have been exposed to naphthalene in liquid form through their skin and inhaled naphthalene vapors have developed abnormalities in the blood and liver. Since polycyclic aromatic hydrocarbons enter the water through industrial discharge and sewage treatment plants, most are not easily dissolved in water. Still, they are adsorbed into solid particles and settle to the bottom of lakes and rivers. After a period of time, the microorganisms in the river help decompose polycyclic aromatic hydrocarbons in the soil or water. However, the contaminated water is uptake by plants and animals. PAHs continuously accumulate in their bodies. When humans eat those plants and animals, PAHs get into the human body. The Department of Health and Human Services in the United States (DHHS) has determined that 
certain PAHs are reasonably expected to be carcinogens. If humans ingested food with PAHs, it might cause stomach cancer and other diseases.

\section{Gas chromatography-mass spectrometry analysis}

Quantitative analysis requires GC analysis to know whether the concentration of PAHs affected the adsorption properties of the gel. It helps to separate different kinds of PAHs that consist in the sample and distinguish them by the retention time or MS detector. LLE is used for extracting the sample water into the organic part, aqueous part, and an organic part transfer into the GC vial. The concentration of PAHs inside the sample water is calculated by a calibration curve. These are calibrated by the setting working solution and mixing the standard stock solution of NAP, PHE, and PYR at 20 ppb, 50 ppb, 100 ppb, 150 ppb, and $200 \mathrm{ppb}$. GCMS analysis was performed on a 6890 Series Plus Gas Chromatograph equipped with an Agilent 7683 Autosampler, which was used in conjunction with a 5973N Mass Selective Detector (Agilent Technologies, Palo Alto, CA, USA). Use MSD ChemStation software D.03.00 (Agilent technology) to analyze the data. Chromatographic separation was performed on a J\&W DB 5MS UI capillary column $(30 \mathrm{~m} \times 0.25 \mathrm{~mm}$ ID, $0.25 \mu \mathrm{m}$ thick; Agilent Technologies).

\section{Conclusions}

A physical gel is proposed as the simplest method for dealing with the PAHs wastewater. Vinegar is used as a basic solvent for forming gelatin gel. Physical gel properties are much soluble than the other gels, with high efficiency for absorbing PAHs and the household wastewater on cooking utensils to prevent PAHs from exposure to the environment.

\section{Funding}

The Open University of Hong Kong Research Grant (No. 2020/1.19).

\section{Acknowledgments}

The work described in this paper was fully supported by the Open University of Hong Kong Research Grant (No. 2020/1.19).

\section{Conflicts of interest}

The authors have no conflicts of interest to disclose.

\section{References}

1. Fernández, I. Understanding the reactivity of polycyclic aromatic hydrocarbons and related compounds. Chem Sci 2020, 11, 3769-3779, https://doi.org/10.1039/d0sc00222d.

2. Sun, K.; Song, Y.; He, F.; Jing, M.; Tang, J.; Liu, R. A review of human and animals exposure to polycyclic aromatic hydrocarbons: Health risk and adverse effects, photo-induced toxicity and regulating effect of microplastics. Sci Total Environ 2021, 773, 145403, https://doi.org/10.1016/j.scitotenv.2021.145403.

3. Patel, A.B.; Shaikh, S.; Jain, K.R.; Desai, C.; Madamwar, D. Polycyclic Aromatic Hydrocarbons: Sources, Toxicity, and Remediation Approaches. Front Microbiol 2020, 11, 562813, https://doi.org/10.3389/fmicb.2020.562813. 
4. Chan, M. N.; Luan, T. G.; Wong, M. H.; Tam, F. Y. Removal and biodegradation of Polycyclic aromatic hydrocarbons by a microalgal species selenastrum capricornutum. Environ. Toxicol. Chem 2006, 25, 17721779, https://doi.org/10.1897/05-354r.1.

5. Pearlman, R.S.; Yalkowsky, S.H.; Banerjee, S. Water solubilities of polynuclear aromatic and heteroaromatic compounds. J. phys. chem. Ref. Data 1984, 13, 555-562, https://doi.org/10.1063/1.555712.

6. Wilson, S.C.; Jones, K.C. Bioremediation of soil contaminated with polynuclear aromatic hydrocarbons (PAHs): A review. Environ Pollut 1993, 81, 229-49, https://doi.org/10.1016/0269-7491(93)90206-4.

7. Alegbeleye, O.O.; Opeolu, B.O.; Jackson, V.A. Polycyclic Aromatic Hydrocarbons: A Critical Review of Environmental Occurrence and Bioremediation. Environ Manage 2017, 60, 758-783, https://doi.org/10.1007/s00267-017-0896-2.

8. Puszkarewicz, A.; Kaleta, J. The Efficiency of the Removal of Naphthalene from Aqueous Solutions by Different Adsorbents. Int J Environ Res Public Health 2020, 17, 5969, https://doi.org/10.3390/ijerph17165969.

9. Parab, V.; Phadke, M. Co-biodegradation studies of naphthalene and phenanthrene using bacterial consortium. J Environ Sci Health A Tox Hazard Subst Environ Eng 2020, 55, 912-924, https://doi.org/10.1080/10934529.2020.1754054.

10. Patel, A.B.; Shaikh, S.; Jain, K.R.; Desai, C.; Madamwar, D. Polycyclic Aromatic Hydrocarbons: Sources, Toxicity, and Remediation Approaches. Front Microbiol 2020, 11, 562813, https://doi.org/10.3389/fmicb.2020.562813.

11. Girardin, V.; Grung, M.; Meland, S. Polycyclic aromatic hydrocarbons: bioaccumulation in dragonfly nymphs (Anisoptera), and determination of alkylated forms in sediment for an improved environmental assessment. Sci Rep 2020, 10, 10958, https://doi.org/10.1038/s41598-020-67355-1.

12. Kamelia, L.; de Haan, L.; Spenkelink, B.; Bruyneel, B.; Ketelslegers, H.B.; Boogaard, P.J.; Rietjens, I.M.C.M. The role of metabolism in the developmental toxicity of polycyclic aromatic hydrocarboncontaining extracts of petroleum substances. J Appl Toxicol 2020, 40, 330-341, https://doi.org/10.1002/jat.3906.

13. Nzila, A.; Musa, M.M. Current Status of and Future Perspectives in Bacterial Degradation of Benzo[a]pyrene. Int J Environ Res Public Health 2020, 18, 262, https://doi.org/10.3390/ijerph18010262.

14. Liu, D.; Nikoo, M.; Boran, G.; Zhou, P.; Regenstein, J.M. Collagen and gelatin. Annu Rev Food Sci Technol 2015, 6, 527-57, https://doi.org/10.1146/annurev-food-031414-111800.

15. He, Y.; Wang, C.; Wang, C.; Xiao, Y.; Lin, W. An Overview on Collagen and Gelatin-Based Cryogels: Fabrication, Classification, Properties and Biomedical Applications. Polymers 2021, 13, 2299, https://doi.org/10.3390/polym13142299.

16. Younes, I.; Rinaudo, M. Chitin and chitosan preparation from marine sources. Structure, properties and applications. Mar Drugs 2015, 13, 1133-74, https://doi.org/10.3390/md13031133.

17. Patiño-Ruiz, D.A.; De Ávila, G.; Alarcón-Suesca, C.; González-Delgado, Á.D.; Herrera, A. Ionic Cross-

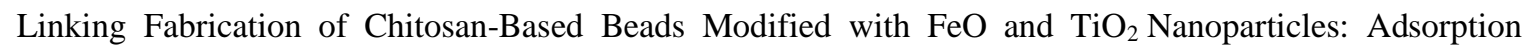
Mechanism toward Naphthalene Removal in Seawater from Cartagena Bay Area. ACS Omega 2020, 5, 26463-26475, https://doi.org/10.1021/acsomega.0c02984.

18. Roslycky, E.B. Reliable procedure for silica gel preparation. Appl Microbiol. 1972, 24, 844-845, https://www.ncbi.nlm.nih.gov/pmc/articles/PMC380676.

19. Vu-Duc, N.; Phung, Thi. LA.; Le-Minh, T.; Nguyen, LA.; Nguyen-Thi, H.; Pham-Thi, LH.; Doan-Thi, VA.; Le-Quang, H.; Nguyen-Xuan, H.; Thi, Nguyen. T.; Nguyen, P.T.; Chu, D.B. Analysis of Polycyclic Aromatic Hydrocarbon in Airborne Particulate Matter Samples by Gas Chromatography in Combination with Tandem Mass Spectrometry (GC-MS/MS). J Anal Methods Chem 2021, 2021, 6641326, https://doi.org/10.1155/2021/6641326.

20. Kim, D.Y.; Kim, B.; Shin, H.S. Reduction of Polycyclic Aromatic Hydrocarbons (PAHs) in Sesame Oil Using Cellulosic Aerogel. Foods 2021, 10, 644, https://doi.org/10.3390/foods10030644.

21. Conesa, J.A.; Nuñez, S.S.; Ortuño, N.; Moltó, J. PAH and POP Presence in Plastic Waste and Recyclates: State of the Art. Energies 2021, 14, 3451, https://doi.org/10.3390/en14123451.

22. Zeng, Y.; Hong, P. K. A.; Wavrek, D. A. Chemical-biological treatment of pyrene. Water Res 2000, 34, 1157 1172, https://doi.org/10.1016/S0043-1354(99)00270-5.

23. Brown, G.S.; Barton, L.L.; Thomson, B.M. Permanganate oxidation of sorbed polycyclic aromatic hydrocarbons. J. Waste Manag 2003, 23, 737-740, https://doi.org/10.1016/S0956-053X(02)00119-8. 
24. Azadi, D.; Shojaei, H. Biodegradation of polycyclic aromatic hydrocarbons, phenol and sodium sulfate by Nocardia species isolated and characterized from Iranian ecosystems. Sci Rep 2020, 10, 21860, https://doi.org/10.1038/s41598-020-78821-1.

25. Man, Y.B.; Chow, K.L.; Cheng, Z.; Mo, W.Y.; Chan, Y.H.; Lam, J.C.W.; Lau, F.T.K.; Fung, W.C.; Wong, M.H. Profiles and removal efficiency of polycyclic aromatic hydrocarbons by two different types of sewage treatment plants in Hong Kong. J Environ Sci (China) 2017, 53, 196-206, https://doi.org/10.1016/j.jes.2016.04.020.

26. Gulkowska, A.; Leung, H.W.; So, M.K.; Taniyasu, S.; Yamashita, N.; Yeung, L.W.; Richardson, B.J.; Lei, A.P.; Giesy, J.P.; Lam, P.K. Removal of antibiotics from wastewater by sewage treatment facilities in Hong Kong and Shenzhen, China. Water Res 2008, 42, 395-403, https://doi.org/10.1016/j.watres.2007.07.031.

27. Environmental Protection Department. Toxic substances monitoring in Hong Kong, Retrieved from https://www.epd.gov.hk/epd/english/environmentinhk/water/hkwqrc/waterquality/toxic.html,

2008, https://www.epd.gov.hk/epd/english/environmentinhk/water/hkwqrc/waterquality/toxic.html.

28. Zelinkova, Z.; Wenzl, T. The Occurrence of 16 EPA PAHs in Food - A Review. Polycycl Aromat Compd 2015, 35, 248-284, https://doi.org/10.1080/10406638.2014.918550.

29. Agency for Toxic Substances and Disease Registry (ATSDR). Toxicological Profile for Polyaromatic hydrocarbons-Update US Department of Health and Human Services. Atlanta, GA 1995, 150-155, https://www.atsdr.cdc.gov/toxprofiles/tp69.pdf. 